\title{
O ESPAÇO DA TROCA: A COMUNICAÇÃO SEM PALAVRAS NA TRILOGIA XENOGENESIS DE OCTAVIA BUTLER
}

\author{
André Cabral de Almeida Cardoso
}

Emumadascartasquecompõem Lanouvelle Héloïse, romanceepistolar publicado por Rousseau em 1761, Saint-Preux, um dos protagonistas, descreve para seu amigo Milord Édouard uma manhã que passou junto de Julie, sua antiga amante, e de M. de Wolmar, com quem ela agora está casada, na propriedade dos dois em Clarens. Trata-se da famosa passagem da matinée à l'anglaise, um café da manhã íntimo, do qual participam apenas os donos da casa e seu convidado, que se servem sozinhos, sem a presença de criados. É justamente a ausência de estranhos, como explica Saint-Preux a Milord Édouard, que garante a intimidade da situação: sem ninguém para observá-los ou distraí-los, esses amigos podem se entregar à contemplação e ao recolhimento dentro de si mesmos e, o que é mais importante, ao recolhimento "de um dentro do outro" (ROUSSEAU, 1993, vol. 2, parte 5, carta 3, p. 184). Sem ninguém de fora desse estreito círculo de amizades, eles podem dizer o que quiserem sem constrangimento, ou, melhor ainda, podem simplesmente não dizer nada. Para Saint-Preux, aliás, a amizade não pode ser expressa por palavras:

Mais l'amitié, Milord, l'amitié! Sentiment vif et celeste, quels discours sont dignes de toi? Quelle langue ose être ton interprète? Jamais ce qu'on dit à son ami peut-il valoir ce qu'on sent à ses côtés? Mon Dieu! Qu'une main serrée, qu'un regard animé, qu'une étreinte contre la poitrine, que le soupir qui la suit 
disent de choses, et que le premier mot qu'on prononce est froid après tout cela! (ROUSSEAU, 1993, vol. 2, parte 5, carta 3, p. 183). ${ }^{1}$

Trata-se, portanto, de dizer o inexprimível, mas o inexprimível apenas em palavras, pois há uma comunicação mais satisfatória através de gestos, de olhares, ou de uma vaga reverberação íntima da amizade. Esse café da manhã íntimo, que traz todas as marcas dos pequenos confortos burgueses (a comida agradável, a leitura dos jornais depois do café, a dona de casa que borda tranquilamente perto das janelas enquanto observa os filhos se distraírem com um livro de figuras), oferece a Saint-Preux e ao casal de Wolmar a oportunidade de se entregar à circulação de seus sentimentos. É assim que, um pouco mais adiante, os três podem compartilhar da mesma emoção quando Julie ouve de seu marido um comentário particularmente carinhoso:

À ce mot, son ouvrage est tombé de ses mains; elle a tourné la tête, et jeté sur son digne époux um regard si touchant, si tendre, que j'en ai tressailli moimême. Elle n'a rien dit: qu'eût-elle dit qui valût ce regard? Nos yeux se sont aussi rencontrés. J'ai senti à la manière dont son mari m’a serré la main que la même émotion nous gagnait tous trois, et que la douce influence de cette âme expansive agissait autour d'elle, et triomphait de l'insensibilité même. (ROUSSEAU, 1993, vol. 2, parte 5, carta 3, p. 185).²

A emoção que toma os três amigos não chega a ser nomeada ou descrita; trata-se de um afeto mútuo, mas seu conteúdo exato não pode ser descrito por palavras. O que conta aqui realmente é o processo através do qual essa emoção é comunicada e circula entre os três amigos. No entanto, se aquilo que é comunicado não pode ser explicitado através da linguagem e permanece de certa forma em abstrato, isso não significa que o meio de comunicação é imaterial; ao contrário, ele está calcado em processos físicos, na troca de olhares, no toque das mãos que se cerram. Em outras

1 "Mas a amizade, Milord, a amizade! Sentimento vivo e celestial, que discursos são dignos de ti? Que língua ousa ser teu intérprete? O que se diz a um amigo pode, alguma vez, valer aquilo que se sente ao seu lado? Meu Deus! Como um aperto de mão, um olhar vivo, um abraço contra o peito, o suspiro que o segue dizem coisas, e como a primeira palavra que se pronuncia parece fria depois disso tudo!" Tradução livre.

2 "Quando isso foi dito, seu trabalho tombou de suas mãos; ela voltou o rosto e lançou ao seu digno esposo um olhar tão tocante, tão afetuoso, que eu mesmo estremeci. Ela não disse nada: o que ela poderia ter dito que equivaleria àquele olhar? Nossos olhos também se encontraram. Senti pela maneira como seu marido me apertou a mão que a mesma emoção tomava conta de nós três, e que a doce influência daquela alma expansiva agia ao seu redor, e vencia até mesmo a insensibilidade." Tradução livre. 
palavras, se as línguas se calam, pois a linguagem verbal não é adequada para transmitir aquilo que se quer dizer, agora são os corpos que falam. Uma certa presença erótica do corpo ainda se faz sentir nas palavras usadas por Saint-Preux para descrever essa experiência, na sua menção a abraços apertados contra o peito, aos suspiros que eles provocam, a toques e olhares que causam estremecimentos, mas se trata de um erotismo sublimado e disperso entre vários sujeitos, incluindo Milord Édouard, para quem Saint-Preux escreve, e o próprio leitor invisível das cartas que compõem o romance. Na verdade, esse processo de sublimação está no cerne de $L a$ nouvelle Hélö̈se, que conta a história do envolvimento amoroso e sexual entre Saint-Preux e Julie, interrompido pela interdição do pai da moça, que é obrigada a casar com $\mathrm{M}$. de Wolmar. Depois disso, o romance narra o desespero de Saint-Preux e sua luta para controlar sua paixão por Julie e transformá-la numa conexão mais racional e aceitável socialmente, que lhe permitiria participar da pequena comunidade sentimental formada na casa dos Wolmar em Clarens, comunidade que inclui, além de Julie e M. de Wolmar, Édouard e Claire, amiga de infância de Julie, juntamente com seus filhos e criados.

Clarens surge, assim, como uma pequena comunidade utópica em La nouvelle Héloïse, um exemplo de felicidade e dos ideais de Rousseau a respeito da harmonia social, da educação das crianças e da organização do trabalho. Como nas utopias tradicionais, os hábitos e o funcionamento dessa comunidade são descritos em pormenores que envolvem todos os aspectos da vida de seus integrantes, incluindo seu lazer, sua alimentação e suas relações pessoais, todos expostos aos olhos de um visitante, Saint-Preux, que os comenta e os compara - de forma favorável - com os costumes da sociedade mais ampla, que é também a sociedade dos leitores do romance. ${ }^{3}$ A base dessa comunidade de contornos utópicos é o tipo de comunicação sentimental que acabo de descrever e as afinidades

3 Tanto Jameson (2007) quanto Moylan (2000) chamam atenção para o caráter sistêmico da utopia, que envolve uma visão totalizante do corpo social - ainda que, para Moylan, chegar de fato a uma visão total de um sistema social seja impossível e a análise totalizante em que o texto utópico está baseado mantenha-se, portanto, sempre em aberto (pp. 64-65). De qualquer forma, como Jameson indica, o pensamento utópico partiria da premissa de que cada característica da sociedade está ligada a todas as outras, de modo que a utopia implicaria sempre a mudança do sistema como um todo (p. 39). Daí a tendência de textos utópicos descreverem em pormenores a sociedade que imaginam, submetendo cada detalhe da vida de seus habitantes a alguns princípios básicos. Essa estrutura do texto utópico é reproduzida nos trechos de La nouvelle Hélö̈se que tratam da comunidade de Clarens. 
que ela engendra, sendo ela própria vista como uma espécie de ideal que a comunidade de Clarens vem realizar e agindo, ao mesmo tempo, como o cimento social que une os vários membros dessa comunidade. Trata-se, como já foi dito, de uma comunicação sem palavras, em que a circulação de sentimentos é assegurada pela empatia e pela sensibilidade, que permite ao indivíduo "ler" os sinais emitidos pelo outro, tornando-o extremamente receptivo aos estímulos de seu meio. Em seu estágio mais apurado, esse tipo de comunicação leva a um estado de perfeita transparência, em que os movimentos internos do indivíduo tornam-se visíveis para aqueles à sua volta (pelo menos aqueles que gozam da sensibilidade necessária para percebê-los), de modo que estes sejam compartilhados pelo grupo, como na matinée à l'anglaise.

Em última instância, esse processo de expressão e circulação de sentimentos acaba por relativizar não só as fronteiras entre o que é interno e o que é externo, mas também entre diferentes indivíduos. $\mathrm{O}$ processo de sublimação dos impulsos eróticos de Saint-Preux é significativo nesse aspecto. Ele envolve uma reorganização da subjetividade de Saint-Preux, que se estrutura numa interação entre o próprio Saint-Preux, M. de Wolmar e Julie. O controle e modificação de suas paixões, que lhe permitem encontrar seu lugar na comunidade de Clarens - onde, como uma realização em microcosmo da "melhor ordem das coisas" (ROUSSEAU, 1993, vol. 2, parte 5, carta 3, p. 189), uma imagem da harmonia universal, cada um tem um lugar e uma função definidos - passam pelo recolhimento "de um dentro do outro", num processo em que, através da empatia e da identificação, Saint-Preux pode absorver os valores de Julie e M. de Wolmar e se moldar à sua imagem. Como Dorothea von Mücke observa, a criação da comunidade utópica de Clarens depende da internalização da autoridade de Wolmar e de seu olhar vigilante (VON MÜCKE, 1991, p. 141). É através do processo de identificação promovido pela circulação de sentimentos que a autoridade e o olhar do outro tornam-se elementos internos ao indivíduo. Ao mesmo tempo, a transparência estabelecida nesse processo garante que todos estão submetidos a uma visão e a um controle mútuos. Como Saint-Preux observa, na matinée à l'anglaise "[il] n'est rien resté dans les fonds des cœurs qu'on veuille se cacher l'un à l'autre" (ROUSSEAU, 1993, vol. 2, parte 5, carta 3, p. 182). ${ }^{4}$

Von Mücke argumenta que para Rousseau a autoridade e a moral não podem se opor ao desejo, sob pena de se tornarem elementos puramente

4 "Não ficou nada no fundo dos corações que se quisesse esconder um do outro." Tradução livre. 
externos ao indivíduo. Sendo assim, o caminho da virtude para o homem não é a proibição do desejo, mas sim a sua disciplina, que se dá através da ligação a uma mulher idealizada (pp. 51-52, 122). Julie, ao assumir o papel de foco e modelo da circulação sentimental, desempenha um papel central nesse processo. Ela dá origem ou funciona como elemento transmissor da corrente de sentimentos, como na cena da matinée à l'anglaise descrita acima, em que sua afeição, ao circular entre Saint-Preux e Wolmar, forma uma espécie de feedback loop em que essa afeição é intensificada, levando os três amigos ao silêncio da experiência compartilhada, e empurrando Saint-Preux a sublimar seu desejo ao se identificar com o carinho conjugal dos dois esposos. Mais ainda, ao se converter de um objeto de desejo em um objeto de identificação, ela faz com que todos à sua volta assumam as suas características; como Saint-Preux e outros personagens comentam diversas vezes ao longo do romance, é impossível se aproximar de Julie sem se tornar, de certa forma, a própria Julie.

Muitos dos elementos presentes no ideal de comunicação delineado em La nouvelle Héloïse, e que acabaram se tornando componentes fundamentais da cultura sentimental do século XVIII, incluindo a centralidade da sensibilidade e da empatia, a circulação de sentimentos, a presença da transparência e o apagamento da fronteira entre os indivíduos, também estão presentes em Xenogenesis, de Octavia Butler, trilogia de ficção científica publicada na segunda metade da década de $1980 .^{5}$ Não pretendo postular que houve uma influência direta do romance sentimental do século XVIII sobre a narrativa de Octavia Butler, ${ }^{6}$ mas

5 A trilogia é formada pelos romances Dawn (1987), Adulthood Rites (1988) e Imago (1989). Neste artigo, usei como base a edição da Grand Central Publishing, publicada originalmente em 200o, que reúne os três romances sob o título Lilith's Brood.

6 Nas entrevistas concedidas por Octavia Butler que tive a oportunidade de ler não há nenhuma referência à literatura do século XVIII. Entretanto, várias das opiniões expressas por Butler revelam uma visão da leitura e da escrita que lembra algumas das posições centrais do código sentimental, muitas delas perpetuadas na nossa cultura desde o romantismo. Dentre elas, pode-se apontar uma ideia da escrita como expressão do eu e uma certa identificação da autora com a sua própria obra, de tal forma que Butler via as recusas de publicarem seus textos no início da carreira como uma rejeição a ela própria. $\mathrm{O}$ texto seria resultado de uma expressão mais ou menos espontânea da emoção da escritora: "Qualquer coisa que acontece e que desperta uma reação emocional em você com quase toda certeza aparece na sua escrita" ("Anything that happens that makes you emotional is almost certain to come out in your writing"). A essa ideia se alia a crença numa possível reverberação emocional entre autora e leitor (ROWELL e BUTLER, 1997, pp. 48-49); a leitura não seria simplesmente um exercício intelectual, mas exigiria também a empatia do leitor. A respeito de Kindred, livro publicado originalmente em 1979 e, portanto, anterior à trilogia Xenogenesis, Butler declara: "The idea really was to make people feel the book" ("A ideia era fazer com que as pessoas sentissem o livro") (BUTLER, 2003). 
julgo interessante que os mesmos elementos oriundos do paradigma sentimental ocupem uma posição central em obras pertencentes a gêneros tão diferentes e escritas em momentos tão distintos, principalmente na medida em que, em ambos os casos, eles servem de base para um projeto utópico. Dar atenção a esses elementos talvez torne possível encontrarmos pontos de contato entre esses dois momentos tão diferentes, mas ambos marcados pelo surgimento de novas epistemologias e por profundas transformações econômicas e sociais, com a consolidação da burguesia e a Revolução Industrial no século XVIII, e o surgimento do capitalismo globalizado no final do século XX.

Em Xenogenesis, uma raça de alienígenas, os Oankali, resgatam os poucos sobreviventes da raça humana, depois de a Terra ter sido praticamente destruída numa guerra nuclear que deixou o planeta inabitável. O primeiro romance da trilogia, Dawn, se inicia com a protagonista, Lilith Iyapo, despertando depois de duzentos anos de hibernação a bordo da nave Oankali. Lilith passa por uma série de interrogatórios, confinada num quarto vazio que lembra uma cela de prisão, até se ver na presença de Jdahya, o primeiro Oankali a que é apresentada. Há, então, a passagem de uma situação de completa sujeição e alienação para outra de interação em que a economia do olhar e do poder se modifica: se antes Lilith não podia ver seus captores, ouvindo apenas suas vozes em entrevistas completamente controladas pelos alienígenas, agora ela pode ter contato direto com eles; e, enquanto antes ela era simples objeto de sua observação, agora a observação se torna recíproca, e um verdadeiro diálogo se estabelece. A autoridade dos Oankali, que no início parecia distante e cruel, se humaniza, ainda que fique claro que o poder continua nas mãos dos alienígenas. Trata-se, porém, de um poder que se revela benevolente ou mesmo caridoso. Jdahya demonstra uma autêntica preocupação com os humanos capturados pelos Oankali e o desejo de preservá-los, salvando-os da destruição da Terra. Relata também esforços para curá-los de suas doenças e de estender-lhes a vida; a própria Lilith tinha sido curada de um câncer incipiente de origem genética.

Como na comunidade de Clarens em La nouvelle Héloïse, calcada na autoridade benéfica do patriarca Wolmar, o poder não se delineia mais pela imposição da força, como nas primeiras páginas de Dawn, mas se metamorfoseia no cuidado atencioso - mas sempre controlador - que os pais exercem sobre seus filhos. Do mesmo modo, a autoridade dos Oankali não se sustenta simplesmente através da superioridade de seu poderio tecnológico, ainda que esse elemento permaneça presente - assim como a autoridade de Wolmar não se valia apenas do apoio hierárquico da família enquanto instituição social. Em ambos os casos, a autoridade está 
calcada sobretudo na sua excelência moral, trazida para uma posição de destaque como elemento de legitimação. Assim, Jdahya convence Lilith de que os Oankali desconhecem a noção de guerra, não têm interesse na dominação e escravização, têm um profundo respeito à vida e são avessos à agressividade - traços que oferecem um contraste gritante com o comportamento dos humanos, que praticamente haviam destruído a si mesmos e a seu planeta na guerra. Mesmo o isolamento anterior de Lilith é explicado como um período de adaptação e cura (BUTLER, 2007, p. 18), e as entrevistas com Jdahya são também terapêuticas, uma tentativa de deixar Lilith se familiarizar aos poucos com a aparência alienígena (e repulsiva) dos Oankali. Além disso, também como na comunidade de Clarens, a autoridade se consolida através de elos pessoais. Jdahya menciona para Lilith uma médica humana com quem os Oankali haviam convivido durante décadas em sua nave, e que se tornara uma mãe para Jdahya e seus irmãos. Ao longo de toda a trilogia Xenogenesis, a inserção de humanos na sociedade Oankali se dá através do estabelecimento de laços afetivos e familiares como esse.

A passagem do total isolamento de Lilith para sua interação direta com Jdahya e, logo depois, com o resto da família do alienígena, marca também uma mudança no tom da narrativa, que passa de um relato de cativeiro, com sua evocação sombria de interrogatórios conduzidos por governos autoritários, para um relato formalmente mais próximo das narrativas utópicas, com Lilith desempenhando o papel do viajante que chega à utopia e tenta compreender avidamente a estrutura da sociedade que encontra, expressando seu estranhamento e estabelecendo comparações com sua sociedade de origem. É significativo que o tom utópico surja no momento em que se estabelece um diálogo entre Lilith e Jdahya, uma vez que a comunicação e a troca se estabelecem como elementos utópicos centrais em Xenogenesis. Jdahya explica a Lilith a natureza e o objetivo dos alienígenas: eles são uma raça itinerante que busca outras raças inteligentes com as quais possam trocar seu material genético. Desse modo, eles se renovam constantemente, mudando tanto o seu genótipo quanto o seu fenótipo de geração em geração, evitando uma especialização excessiva que no seu entender levaria à imobilidade e à morte. Na verdade, porém, os Oankali não se transformam apenas para se adaptar, e sim, mais fundamentalmente, para se tornarem outros; ou seja, sua metamorfose não tem um fim teleológico, constituindo-se num ideal em si mesmo (WHITE, 1993, p. 404). A palavra que Jdahya usa para traduzir o nome "Oankali" é "traders", que remete diretamente ao perpétuo movimento de troca genética em que estão engajados (uma vez que o verbo "to trade" significa "trocar"), mas cujo sentido mais 
corrente em inglês é "mercadores". É interessante observar que uma retórica oriunda do mercado é empregada aqui para descrever a relação dos Oankali com as outras raças que encontram, reforçada pela ideia de aquisição para se referir à absorção de material genético novo. Temos aí novamente um paralelo com a cultura sentimental do século XVIII, em que, segundo Gillian Skinner, a operação da sensibilidade e a circulação de sentimentos que ela promovia, estabelecendo elos sociais, também era descrita em termos econômicos. Na cultura sentimental, o dinheiro era um símbolo ambivalente: por um lado, representava o apego a bens materiais, a corrupção do caráter e o domínio das aparências; por outro, era um meio de praticar a caridade e de expressar a preocupação com o próximo ao aliviar sua miséria, estabelecendo contatos sociais entre classes diferentes. Para Barker-Benfield, a circulação de dinheiro e mercadorias ajuda a transformar os hábitos e a identidade social dos indivíduos no século XVIII, substituindo as antigas hierarquias feudais por uma visão de mundo calcada em transações, na mobilidade e no encontro com o novo. $\mathrm{O}$ dinheiro surge, assim, como elemento de troca capaz de traduzir uma mercadoria por outra, uma espécie de linguagem universal que garante a interação entre os diversos elementos sociais (BARKER-BENFIELD, 1996, p. 84-85). Em Xenogenesis, portanto, o mercado também serve como modelo simbólico para o estabelecimento de vínculos interpessoais, interraciais e interculturais, e está intimamente relacionado à própria identidade dos Oankali, que se definem pela troca, num processo em que são ao mesmo tempo mercador e mercadoria; eles trocam (ou comercializam) a si mesmos, segundo Jdahya (BUTLER, 2007, p. 24). A identidade dos Oankali, portanto, é essencialmente fluida, pois se encontra em constante transformação devido à troca genética que exercem com outras espécies; mais importante, esse modelo de identidade é o ideal que impulsiona os Oankali.

Esse ideal de identidade não demora a assumir contornos utópicos em Xenogenesis. Praticamente todos os críticos que comentam a trilogia de Octavia Butler veem na subjetividade fluida dos Oankali não só uma aceitação, mas uma busca da diferença, uma quebra de hierarquias que desestabiliza as estruturas de poder humanas, promovendo um senso de comunidade mais harmônico e igualitário ao privilegiar a colaboração e a formação de conexões em lugar da competição e do domínio.7 De fato, os Oankali são essencialmente simbióticos, trocando a disputa

7 Cf., por exemplo, Ackerman (2008), Alaimo (1996), Clarke (2008), Goss e Riquelme (2007), Jacobs (2003), Peppers (1995), Sands (2003) e White (1993). 
pela união com outras espécies; desconhecendo a guerra, só usam de violência para a autodefesa e, mesmo nesses casos, imediatamente procuram curar os atacantes que tenham ferido. Como em utopias tradicionais, cujos habitantes oferecem um contraponto moral para uma sociedade corrompida, os Oankali fornecem um claro contraponto à espécie humana. Sua busca pela conciliação e a absorção das diferenças é colocada em oposição à contradição genética que eles percebem nos seres humanos, divididos entre a inteligência e o instinto hierárquico, que os leva à tentativa de dominação, à violência, e, finalmente, à autodestruição. Como os próprios Oankali, a narrativa de Xenogenesis se apropria de traços típicos das utopias clássicas para caracterizar a sociedade dos alienígenas: erradicação de doenças e medicina avançada, extensão da vida, controle do mundo natural, forte senso de comunidade, abundância de alimentos e recursos, trabalho desconectado do excesso de esforço e da exploração, ausência da dominação social, presença de paisagens idílicas dentro da nave Oankali, que se apresenta como um espaço utópico e protegido, isolado de um universo hostil. Muitas das características da sociedade Oankali, aliás, são uma realização das esperanças utópicas expressas na lista de futuros avanços científicos que encerra a New Atlantis, de Francis Bacon. No entanto, como observa Naomi Jacobs, é na subjetividade fluida dos Oankali, representada principalmente pelos híbridos dos alienígenas com humanos, que se concentram as esperanças utópicas de Xenogenesis; e é aqui que encontramos uma retomada, quase que ponto por ponto, do projeto de comunicação sentimental delineada por Rousseau em La nouvelle Héloïse, e do tipo de identidade relacional que esta acarreta.

As possibilidades abertas pela ficção científica, na verdade, permitem exacerbar muitos dos elementos centrais do paradigma sentimental adotado por Rousseau, calcando-os ainda mais no corpo e aprofundando seu potencial utópico. A sensibilidade, que na literatura sentimental estabelece uma ponte entre o mundo moral e o mundo físico dos sentidos, torna-se, por exemplo, um componente central da fisiologia dos Oankali e de seus híbridos. Cobertos por tentáculos sensórios, eles se encontram permanentemente abertos aos estímulos do mundo externo: eles nunca podem deixar de ver e sua audição é extremamente apurada. Se, como já vimos, na literatura sentimental o toque é um meio de comunicação mais intenso e mais eficaz do que as palavras, no caso dos Oankali e seus híbridos essa tendência é aprofundada, pois seu toque literalmente penetra a superfície dos outros corpos e dos objetos do mundo físico. Seus tentáculos sensoriais atravessam a pele, o que lhes permite "ler" diretamente os impulsos fisiológicos e emocionais dos seres vivos com que entram em contato, incluindo sua estrutura genética. Se em La nouvelle 
Héloïse a identificação e a empatia promoviam uma certa permeabilidade das fronteiras entre os indivíduos, em Xenogenesis essas fronteiras são efetivamente apagadas, realizando de forma concreta a fusão de diferentes subjetividades almejada pela literatura sentimental. ${ }^{8}$ Da mesma maneira, a desconfiança em relação à linguagem verbal é reforçada, uma vez que a comunicação através de estímulos sensoriais, principalmente o toque, é apresentada como mais eficaz e verdadeira. A linguagem verbal é associada aos humanos e ao seu desejo de dominação, que muitas vezes envolve dissimular a realidade e mentir. Como na matinée à l'anglaise, a verdadeira comunicação se dá de forma silenciosa, intermediada pelo corpo Oankali, que é todo ele uma superfície sensível. Em ambos os casos, a opacidade das palavras é trocada pela transparência de corpos que se falam diretamente.

No entanto, acabo de falar da intermediação de um corpo; trata-se, porém, de uma intermediação que se apaga. Em nenhum ponto isso é mais claro em Xenogenesis do que nos momentos em que se descrevem as relações sexuais envolvendo os Oankali e os humanos. Esses são momentos cruciais, pois é através dessas relações que se dá a troca de material genético entre as espécies e se produzem os híbridos entre humanos e Oankali, que são o foco do projeto utópico delineado na trilogia. Todas as relações sexuais são intermediadas por um ooloi, o terceiro sexo dos Oankali. Os ooloi são engenheiros genéticos naturais, recolhendo e selecionando o material genético dos reprodutores e implantando o óvulo fertilizado - e devidamente programado - no útero em que será gestado. Ao mesmo tempo, o ooloi coloca os parceiros envolvidos em contato um com o outro através dos tentáculos sensoriais que possuem em dois órgãos especiais, dois braços extras semelhantes a trombas de elefante. Através desses "cabos", que lembram cabos de computadores, o ooloi estimula diretamente as áreas do cérebro responsáveis pelo prazer, ao mesmo tempo em que comunica as sensações de um parceiro para o outro. Se desejar, o ooloi pode manipular essas sensações e se apagar, criando a ilusão de que os parceiros estão em contato direto um com o outro. Tornando-se um fio condutor, o ooloi cria uma corrente sensorial fechada, como o feedback loop que vimos em ação entre Saint-Preux, Julie e Wolmar. A dinâmica sexual dos Oankali deixa clara a função dos ooloi como meio de transmissão: eles não contribuem com seu próprio material

8 Quanto ao apagamento entre corpos e individualidades em Xenogenesis e sua ligação com um ideal utópico, cf. Clarke, 2008, p. 93, e Sands, 2003, p. 3. 
genético no ato da fecundação, apenas estabelecem um contato entre os parceiros sexuais.

Assim como em La nouvelle Héloïse, há aqui também um elemento de sublimação erótica, ainda que mais disfarçado. No romance de Rousseau também há um elemento de intermediação que controla e depura as sensações e emoções postas em circulação: a presença de Wolmar como um dos elos condutores da corrente de sentimentos garante que SaintPreux não irá tomar o afeto de Julie como um estímulo erótico; o desejo, assim, converte-se numa forma de afeição mais aceitável que pode romper o dualismo do encontro sexual, que envolveria exclusivamente Saint-Preux e Julie, e pode, então, se disseminar numa comunidade mais ampla, tornando-se o cimento social que une a comunidade de Clarens. Um movimento semelhante se dá nos encontros sexuais narrados em Xenogenesis. Aqui também o encontro exclusivo entre dois parceiros é barrado, e de forma ainda mais drástica do que no romance de Rousseau: depois de entrar em contato sexual com um ooloi, os dois parceiros - sempre de sexos opostos - criam uma aversão física a se tocarem. O encontro sexual se configura, então, numa circulação sensorial semelhante à corrente retratada na matinée à l'anglaise, que envolve uma comunidade mais ampla - nos casos em que se trata efetivamente de produzir um híbrido, ela envolve cinco indivíduos: um casal humano, um casal Oankali e um ooloi. Ao mesmo tempo, se o prazer sensual ainda é parte essencial desse encontro, ele não envolve mais o contato físico e direto entre dois corpos, mas o estímulo e circulação de estímulos sensoriais em seu estado mais puro. Como numa simulação em computador, o sexo se torna virtual; a fecundação não é mais o contato de fluidos corporais, mas a troca e a manipulação de informações. Os parceiros sexuais se tornam voyeurs de seu próprio ato.

Em La nouvelle Hélö̈se, a sublimação tem um papel crucial no controle da paixão, submetendo-a a princípios morais relacionados à racionalidade; em Xenogenesis, ela está ligada à transformação dos impulsos sexuais (incluindo o próprio processo biológico da reprodução) em informação. Para von Mücke, o projeto de uma linguagem transparente na cultura sentimental do século XVIII tinha como objetivo a criação de um sujeito que é pura interioridade, uma presença imediata, uma pura "voz sem corpo" (VON MÜCKE, 1991, p. 66). Esse projeto está calcado na ideia de uma leitura ilusória, em que o meio da escrita se apaga ao evocar imagens e a presença imediata daquilo que representa na mente do leitor. Assim como a transformação do contato sexual em informação em Xenogenesis depende do estabelecimento das tecnologias de informática, das quais retira suas imagens e elementos simbólicos (a interação entre 
ooloi e outros seres, sejam eles humanos, alienígenas ou híbridos, é muitas vezes descrita como um download de informações, por exemplo), a criação de um ideal de leitura transparente no século XVIII também estava calcada na consolidação de uma nova tecnologia: a imprensa e a circulação de romances, que estimulam a leitura privada e silenciosa. A leitura silenciosa criaria a ilusão de imagens que se materializam imediatamente na mente do indivíduo através do exercício de sua própria imaginação, ao contrário da cultura espetacular do teatro, por exemplo, que nunca conseguiria esconder sua condição de representação externa e artificial (VON MÜCKE, 1991, pp. 30-48). Esse mecanismo encontra sua manifestação mais apurada no romance epistolar, do qual La nouvelle Héloïse é um exemplo. Nele, as cartas trocadas entre os personagens são apresentadas como a expressão direta da alma de cada um, sem a intermediação de um narrador e sem a interposição de um estilo rebuscado e estetizante que chame demasiada atenção para si mesmo. ${ }^{9}$ Trata-se, obviamente, de uma situação paradoxal, uma vez que a cultura impressa e os romances dependem da linguagem escrita como meio de comunicação - e não são poucos os romances sentimentais que atacam a linguagem verbal como instrumento de vários engodos. Busca-se, porém, uma linguagem que apague a si mesma, que aja apenas como elemento de ligação entre autor e leitor. Daí o uso disseminado na tradição sentimental de uma linguagem imagística, capaz de evocar a ilusão de uma presença imediata, uma vez que a imagem é vista como uma forma de comunicação mais verdadeira e confiável. Pode-se perceber a mesma situação paradoxal em Xenogenesis. Aqui, porém, as possibilidades abertas pela ficção científica permitem evocar uma forma de comunicação através de imagens e sensações transmitidas (e recebidas) pelos Oankali e os híbridos que formam com os humanos. Capazes de escrever, os Oankali preferem não exercer essa habilidade, que simplesmente exteriorizaria suas experiências e as tornaria alheias a si mesmos; em vez disso, preferem guardá-las em sua memória e compartilhá-las apenas no contato íntimo estabelecido pelo toque. Ao mesmo tempo, a imagem da leitura permanece, já que os Oankali são capazes de "ler" os seres humanos, de compreender seus corpos e suas motivações através do acesso imediato que têm às suas

9 Em seu prefácio a La nouvelle Héloïse (na verdade publicado no fim do romance), Rousseau defende a simplicidade da linguagem empregada por seus personagens e a contrapõe aos exercícios de estilo de um autor preocupado apenas com a forma. As cartas de Saint-Preux e Julie demonstrariam de forma imediata a verdade, numa estética expressiva e não representacional. 
sensações e à sua estrutura genética. A ideia de uma linguagem escrita ressurge, mas trata-se de uma linguagem especial. Se os seres humanos em Xenogenesis são em grande parte definidos pelo seu código genético (e o mesmo pode ser dito dos Oankali), este surge não como uma linguagem que representa o indivíduo, mas sim como uma linguagem que é o indivíduo, uma linguagem perfeitamente interiorizada. Tanto na cultura sentimental quanto em Xenogenesis, a questão a ser evitada é a da interpretação. A linguagem ideal é transparente e livre de ambiguidade, a expressão fiel e imediata da subjetividade interior. Para os Oankali, os humanos são um livro aberto, a tal ponto que Nikanj, o ooloi a que Lilith está ligada, percebe que o corpo dela está disposto a gerar uma criança e prontamente a engravida, ainda que Lilith declare que não deseja isso. A linguagem concreta do corpo é encarada como mais verdadeira que a linguagem verbal. É aos humanos que resta o fardo da interpretação; são eles que persistem em compreender mal as intenções dos Oankali, em se equivocar a respeito de seus atos e em questionar as suas próprias motivações.

Ao discutir a condição do indivíduo no final do século XX, Donna Haraway sugere a noção do corpo como um texto codificado cujos limites seriam estabelecidos numa interação social, através da circulação de informações. Aludindo especificamente à trilogia Xenogenesis, Haraway vê nos Oankali o exemplo de indivíduos que continuam a ter uma importância central não como unidades estanques, mas como nódulos de uma vasta rede interconectada em que o outro torna-se parte íntima do eu. Para Haraway, Xenogenesis fala da "resistência ao imperativo de recriar a imagem sagrada do mesmo" (HARAWAY, 1991, p. 226; tradução minha). Os Oankali e seus híbridos surgem, assim, como uma manifestação ficcional do ciborgue imaginado por Haraway como a encarnação mais radical de uma subjetividade pós-moderna, com toda a sua carga utópica, principalmente no que diz respeito ao prazer envolvido no apagamento de fronteiras (HARAWAY, 1993, p. 316), representado simbolicamente na trilogia de Octavia Butler no ato sexual enquanto troca de informações. A utopia em Xenogenesis encontra seu ponto privilegiado, seu não-lugar imaginário, nesse espaço da troca em que corpos convertidos em códigos podem circular num fluxo descentralizado. O corpo, assim, deixa de ter uma identidade fixa e passa a ser fluido.

De fato, quando chegamos a Imago, o último romance da trilogia, nos deparamos com uma geração final de híbridos entre Oankali e humanos, que são apresentados como uma nova raça, uma realização das esperanças utópicas preparadas ao longo de toda a narrativa. Esse estágio é marcado pelo surgimento dos primeiros ooloi híbridos, que apresentam 
uma habilidade nova, resultado da assimilação dos genes que provocam o câncer nos seres humanos: como consequência da capacidade de células cancerígenas se reproduzirem aleatoriamente, esses novos seres podem mudar de forma. A elasticidade fenotípica dos Oankali, que antes só se manifestava de uma geração para outra, agora pode se manifestar num único indivíduo. Jodahs, o protagonista híbrido de Imago, muda de forma constantemente, a tal ponto que já não é possível dizer que ele possua uma forma própria. A mutabilidade de Jodahs o marca como alguém cuja subjetividade só faz sentido, ou só adquire uma estrutura estável, em relação com os outros: ele tende a assumir a forma daquilo que o cerca, tomando as características daqueles com quem estabelece contato. Como o caso de Aaor, irmã (ou irmão) ${ }^{10}$ de Jodahs, deixa claro, a ausência desse contato faz com que o corpo perca a sua forma, como um canal de comunicação vazio de conteúdo: sem parceiros, Aaor vai perdendo sua forma, até se tornar algo parecido com um gigantesco molusco privado de qualquer identidade própria; sem a interferência de parceiros para estabilizá-lo e dar-lhe forma novamente, Aaor se tornaria uma multidão de organismos unicelulares procurando outros organismos a que poderia se associar de forma simbiótica. Como acontece com aqueles que se aproximam de Julie em La nouvelle Héloïse, esses novos híbridos tornamse aqueles com quem se identificam.

Em Xenogenesis, como na descrição de Donna Haraway do corpo pós-moderno, o corpo é de fato um texto, ou um código. Isso, porém, coloca o corpo numa posição paradoxal. Ao mesmo tempo em que ele ocupa um espaço central na narrativa, tornando-se a base da identidade e da comunicação, sua materialidade, convertida em informação, de certa forma se apaga. Como nas relações sexuais entre humanos e Oankali, o corpo está ao mesmo tempo presente e ausente. Ele é ao mesmo tempo um lugar e um não-lugar, como na formulação de Foucault do corpo utópico, um corpo opaco e ao mesmo tempo transparente, visível e invisível, vida e objeto. Trata-se de um corpo fantasmagórico como o corpo de Julie que, se deixando perpassar por desejos, sentimentos e identificações, torna-se a base da pequena utopia de Clarens, o ponto de contato dos indivíduos que compõem a comunidade. Mas se esse corpo é texto, ele pode não apenas ser lido, mas também reescrito, e o paradoxo do corpo se desdobra. Sua fluidez serve de imagem para a imprevisibilidade e a liberdade, mas também abre a possibilidade da manipulação e o controle. Afinal, é isso o

10 Tanto Aaor quanto Jodahs são ooloi híbridos, ou seja, não pertencem nem ao sexo masculino nem ao feminino. 
que os ooloi fazem ao manipular o material genético das diversas espécies de seres vivos que eles trazem guardado dentro de si como informações codificadas, como se fossem a memória física e viva de um computador. O sonho utópico da fluidez pode trazer escondido dentro de si um outro sonho utópico talvez mais antigo, talvez um pouco mais perverso, e que é um dos alvos centrais das críticas levantadas contra a própria ideia de utopia: o sonho da sociedade controlada, e dos indivíduos manipulados para se encaixarem nela. Nesse sentido, o esboço utópico de Octavia Butler é coerente com as utopias contemporâneas e talvez, na verdade, com toda utopia: ele é fundamentalmente ambíguo.

Parte dessa ambiguidade se deve à delimitação do espaço utópico, uma questão que acompanha a escrita da utopia desde o início. Como Bauman argumenta, as primeiras utopias da era moderna estavam confinadas a um espaço cuidadosamente delimitado, e a imaginação utópica era essencialmente territorial, uma vez que estava atrelada à consolidação da ideia dos Estados nacionais. Hoje, porém, o Estadonação estaria em crise, o que levaria a uma desterritorialização da utopia, que não estaria mais ligada um lugar ideal imaginário (BAUMAN, 2010, pp. 12, 17-22). Nos dois textos considerados neste artigo, podemos ver um movimento semelhante. Na matinée à l'anglaise descrita em La nouvelle Héloïse, há a cuidadosa delimitação de um espaço doméstico e íntimo que focaliza a interação da pequena comunidade de Clarens. Chama atenção aqui a exclusão dos criados, que tem o efeito de eliminar do quadro a questão da hierarquia social (ainda que, em descrições mais amplas do funcionamento de Clarens, os criados encontrem seu lugar nessa pequena ordem social utópica no âmbito da produção). Já aqui, porém, há uma certa desestabilização dos limites físicos desse espaço, uma vez que a comunidade inclui personagens que não estão presentes, mas que participam de sua organização em espírito, através de sua interação por meio das cartas que trocam entre si e dos elos afetivos que estabelecem. Em Xenogenesis, a dispersão no espaço parece maior. Os Oankali já não têm nenhum contato com seu planeta de origem; sua comunidade vagueia espalhada pela galáxia, sem rumo fixo e sem a delimitação de um território preciso. No entanto, imagens de comunidades fechadas e mais ou menos localizadas permanecem, não só na nave Oankali, que forma um ecossistema fechado e protegido dos rigores do espaço interplanetário, mas também nas comunidades de híbridos, humanos e Oankali fundadas na Terra. A essas comunidades se opõem os enclaves de humanos que escolheram não se juntar aos Oankali. Um exercício de exclusão, portanto, também se mantém: aqueles humanos que insistem em manter a sua diferença em relação aos alienígenas e, portanto, recusam a hibridização, 
permanecem fora da comunidade, assim como aqueles que são agressivos ou hierárquicos demais são guardados em animação suspensa dentro da nave Oankali. Cria-se, assim, uma tensão entre territorialização e desterritorialização, entre o ideal da inclusão e a exclusão necessária para o funcionamento da comunidade utópica. Tensões como essa perpassam toda a narrativa de Xenogenesis, sem que elas sejam jamais resolvidas. Num determinado nível, é essencial que as coisas se mantenham assim. Se o impulso utópico da narrativa está centrado na abolição de hierarquias e na valorização das diferenças, na relativização de posições fixas, a ambiguidade deve permanecer como valor em si mesmo, como forma de impedir uma uniformização imobilizadora.

Por outro lado, parte da ambiguidade presente em Xenogenesis se deve às próprias condições de produção da narrativa. Como já vimos, as ideias de circulação e fluidez que são elementos centrais do impulso utópico na obra de Butler estão em grande parte calcadas na lógica do mercado e nas tecnologias de informação, assim como a dissolução de fronteiras que é outro ideal da narrativa pode ser facilmente relacionada ao surgimento de um mercado globalizado. Ainda que a circulação e a intensa comunicação de fato tenham um elemento desestabilizador de hierarquias estanques, parte do caráter opressivo do mercado continua presente. O contato dos Oankali com outras espécies - com todo o ecossistema da Terra, na verdade - se dá através de uma lógica de aquisição. Ainda que preguem a preservação da vida, o que mais importa aos Oankali é o acúmulo de informações genéticas, a tal ponto que a criação de uma nova nave na superfície da Terra acarretará o consumo de toda a biomassa do planeta, deixando apenas uma esfera sem vida. A biodiversidade terrestre, porém, seria preservada na forma de informações genéticas armazenadas nos bancos de dados dos Oankali. De certa forma, a transformação de corpos vivos em informações os transforma em objetos manipuláveis.

Já vimos como uma ambiguidade semelhante estava presente na cultura sentimental do século XVIII, que flutuava entre uma imagem do mercado como condição para a circulação de sentimentos e o contato entre os diversos componentes sociais, e a representação do dinheiro como origem da desigualdade e do apego excessivo aos bens materiais. Isso já pode sugerir algumas explicações para os pontos de contato entre o romance sentimental, representado aqui por La nouvelle Héloïse de Rousseau, e a obra de ficção científica de Octavia Butler. Ambos foram escritos em épocas em que a presença do mercado se fazia sentir de forma mais potente, influenciando a maneira como os indivíduos viam o mundo. No caso de La nouvelle Héloïse, temos a consolidação das relações econômicos e sociais típicas do capitalismo moderno; no caso da trilogia 
Xenogenesis, a intensificação de um mercado globalizado e a flexibilização das relações econômicas, ligados ao predomínio crescente do capital financeiro (que depende justamente do desenvolvimento das tecnologias de comunicação e informação). Nesses dois momentos, a intensificação do papel do mercado na vida cotidiana traz consigo a necessidade de repensar a natureza do indivíduo e sua relação com o corpo social. No século XVIII europeu, assistimos ao surgimento do individualismo burguês e o esfacelamento das antigas hierarquias feudais. Velhas instituições se enfraquecem, e o código de honra aristocrático, calcado em padrões sociais externos, vai cedendo lugar ao código moral burguês, à internalização da autoridade e dos preceitos da boa conduta. O ponto de referência moral é cada vez mais o próprio indivíduo. No capitalismo tardio, o processo de individualização se intensifica e as instituições sociais burguesas se enfraquecem - incluindo aí a própria ideia do Estadonação, cuja influência e autonomia local são enfraquecidas no âmbito de uma economia cada vez mais globalizada. Como Bauman, entre outros teóricos da contemporaneidade, indica, há uma dissolução crescente dos elos sociais e a perda de códigos coletivos capazes de ligar o indivíduo à comunidade. A conduta de cada um passa a se pautar em escolhas pessoais (BAUMAN, 2010).

Nos dois períodos em questão, há, portanto, uma desestabilização da estrutura social vigente e a crise de instituições. Não é de espantar, então, que o elemento de coesão social privilegiado nas duas obras discutidas aqui esteja no bojo do próprio indivíduo, sob a forma de relações pessoais imediatas, formadas através de afinidades subjetivas, que contornam a adesão a instituições ou projetos mais "abstratos" que teriam sua existência fora do indivíduo. Isso se manifesta na própria desestabilização das fronteiras entre interior e exterior, de tal forma que ambos se confundem e tudo se torna, de certa forma, subjetivo. Os diversos pontos em comum entre a tradição sentimental e a ficção científica contemporânea discutidos neste trabalho apontam para a possibilidade de que nossa situação atual não seja tanto a de uma crise no projeto da modernidade, e sim sua continuação, cuja plena realização continua a ser contemplada no horizonte sempre mais distante da utopia.

\section{REFERÊNCIAS BIBLIOGRÁFICAS}

ACKERMAN, Erin M Pryor. Becoming and Belonging: The Productivity of Pleasures and Desires in Octavia Butler's Xenogenesis Trilogy. Extrapolation. Vol. 49, n. 1, 2008. 
ALAIMO, Stacy. Displacing Darwin and Descartes: The Bodily Transgressions of Fielding Burke, Octavia Butler, and Linda Hogan. ISLE: Interdisciplinary Studies in Literature and Environment. Vol. 3, n. 1, 1996.

BACON, Francis. New Atlantis. In: BRUCE, Susan (org.). Three Early Modern Utopias: Utopia, New Atlantis and The Isle of Pines. $1^{\mathrm{a}}$ reimpressão. Oxford: Oxford UP, 2008.

BARKER-BENFIELD, G. J. The Culture of Sensibility: Sex and Society in EighteenthCentury Britain. $1^{\text {a }}$ reimpressão. Chicago e Londres: U of Chicago P, 1996.

BAUMAN, Zygmunt. Utopia with No Topos. History of the Human Sciences. Londres, Thousand Acres, CA e Nova Delhi: SAGE, vol. 16, no. 1, 2003.

. Liquid Modernity. $13^{\mathrm{a}}$ reimpressão. Malden, MA: Polity Press, 2010.

BUTLER, Octavia. A Conversation with Octavia Butler. Entrevista concedida ao site Writers and Books. 2003. Disponível em: http://www.wab.org/events/allofrochester/2003/ interview.shtml. Acessada em: 20/06/2012.

. Lilith's Brood. $1^{\mathrm{a}}$ reimpressão. Nova York e Boston: Grand Central Publishing, 2007.

CLARKE, Bruce. Posthuman Metamorphosis: Narrative and Systems. Nova York: Fordham UP, 2008.

FOUCAULT, Michel. Le Corps utopique. In: Le Corps utopique suivi de Les Hétérotopies. S/c: Lignes, 2009.

GOSS, Theodora e RIQUELME, John Paul. From Superhuman to Posthuman: The Gothic Technological Imaginary in Mary Shelley's Frankenstein and Octavia Butler's Xenogenesis. MFS Modern Fiction Studies. Baltimore: The Johns Hopkins UP, vol. 53, n. 3, 2007 .

HARAWAY, Donna J. The Biopolotics of Postmodern Bodies: Constitutions of Self in Immune Systems Discourse. In: Simians, Cyborgs, and Women: The Reinvention of Nature. Nova York: Routledge, 1991.

. A Cyborg Manifesto. In: DURING, Simon (org.). The Cultural Studies Reader. $3^{\mathrm{a}}$ ed. Londres e Nova York: Routledge, 2007.

JACOBS, Naomi. Posthuman Bodies and Agency in Octavia Butler's Xenogenesis. In: BACCOLINI, Raffaella e MOYLAN, Tom (orgs.). Dark Horizons: Science Fiction and the Dystopian Imagination. Nova York e Londres: Routledge, 2003.

JAMESON, Fredric. Archaeologies of the Future: the Desire Called Utopia and Other Science Fictions. $2^{\mathrm{a}}$ ed. Londres e Nova York: Verso, 2007.

MOYLAN, Tom. Scraps of the Untainted Sky: Science Fiction, Utopia, Dystopia. Boulder, Colorado: Westview Press, 2000.

PEPPERS, Cathy. Dialogic Origins and Alien Identities in Butler's Xenogenesis. Science Fiction Studies. Greencastle, Indiana: SF-TH Inc., vol. 22, n. 1, 1995. 
ROUSSEAU, Jean-Jacques. Julie ou la Nouvelle Héloïse. 2 vols. Folio classique. Paris: Gallimard, 1993.

ROWELL Charles H., e BUTLER, Octavia E. An Interview with Octavia E. Butler. Callaloo. Baltimore: The Johns Hopkins UP, vol. 20, No. 1, 1997.

SANDS, Peter. Octavia Butler's Chiastic Cannibalistics. Utopian Studies. University Park, PA: Penn Univesity P, vol. 14, n. 1, 2003.

SKINNER, Gillian. Sensibility and Economics in the Novel, 1740-180o: The Price of a Tear. Houndmills, GB: Macmillan, 1999.

VON MÜCKE, Dorothea E. Virtue and the Veil of Illusion: Generic Innovation and the Pedagogical Project in Eighteenth-Century Literature. Stanford: Stanford UP, 1991.

WHITE, Eric. The Erotics of Becoming: Xenogenesis and The Thing. Science Fiction Studies. Greencastle, Indiana: SF-TH Inc., vol. 2o, n. 3, 1993. 
